\title{
A relação lazer e mídia entre adolescentes e jovens de escolas públicas em Fortaleza/CE.
}

\author{
Relation between leisure and media among teenagers and young people from public schools of \\ Fortaleza, Ceará.
}

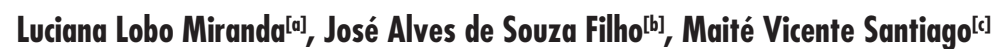

\footnotetext{
${ }^{[a]}$ Doutora em Psicologia pela PUCRJ; professora do Programa de Pós-Graduação em Psicologia da Universidade Federal do Ceará (UFC); coordenadora do projeto de extensão TVEZ: Educação para o uso crítico da mídia.lobo. lu@uol.com.br. Rua Prof. Dias da Rocha 490/503 Meireles. Fortaleza - CE, Brasil.

${ }^{[b]}$ Graduando em Psicologia pela Universidade Federal do Ceará. josefilhoss@gmail.com, Rua Caio Carlos n.178. Benfica. Fortaleza Ceará, Brasil.

${ }^{[c]}$ Graduada em Psicologia pela Universidade Federal do Ceará. Fortaleza Ceará Brasil, mytvicente@gmail.com. Rua Aratuba n. 21 Benfica. Fortaleza Ceará, Brasil.
}

Recebido: 26/08/2013 Received: 08/26/2013

Aprovado: $17 / 09 / 2013$ Approved: 09/17/2013

\section{Resumo}

Com as novas tecnologias, as formas de entretenimento da juventude têm sofrido transformações. Adolescentes e jovens se apropriam da mídia para diversos fins, inclusive para o lazer. 0 objetivo deste artigo é discutir a relação lazer e mídia, com ênfase na internet, entre adolescentes e jovens de escolas públicas de Fortaleza. Trata-se de um estudo de base quantitativa com questionário autoaplicável contendo 77 itens, tematizando família, educação, trabalho, lazer, saúde e mídia, com amostra formada por 1140 sujeitos, entre 14 e 24 anos, de ambos os sexos, estudantes de 43 escolas públicas da cidade de Fortaleza/CE, nos anos de 2010 e 2011. Para análise, utilizou-se o software SPSS, especializado em pesquisas estatísticas em Ciências Sociais. Os dados são discutidos com base em critérios de gênero (masculino e feminino) e etários (menores e maiores de idade). A televisão se sobressaiu em todos os segmentos. No entanto, homens e mulheres ainda possuem formas variadas para se entreter, com destaque para a prática de esporte e jogos entre o gênero masculino. Quanto à internet, ainda há diferença em sua utilização, com maior uso na hora do lazer entre o gênero masculino. Com relação à idade, há diminuição do lazer entre os jovens mais velhos, inclusive relacionada à internet. Por fim, constatou-se que a juventude dispõe de poucos espaços livres de acesso ao lazer. Neste contexto, o lazer mediado pela mídia, sobretudo a televisão e a internet, tem destaque entre adolescentes e jovens, independente de gênero.

Palavras-chaves: Adolescência. Juventude. Lazer. Mídia.

Psicol. Argum. 2014, 32(79), Supl. 2, 29-43 
are discussed on the basis of gender (male and female) and age (under age and major). The television was predominant in all segments. However, men and women still have different ways for entertainment, especially the practice of sports and games among males. The use of the Internet prevailed among males, especially during leisure time. It was noticed a decrease in leisure time among older young people, including the use of the Internet. Finally, it was found that the youth have few free spaces for leisure time. In this context, leisure mediated by the media, especially television and the internet has featured among teenagers and young people, regardless of gender.

Keywords: Teenage. Youth. Leisure. Media.

\section{Introdução}

\section{Adolescência, Juventude, Lazer, Mídia}

Com o advento de novas tecnologias, da virtualização do espaço e da midiatização da sociedade, os modos de subjetivação da juventude têm sofrido mutações, inclusive nas formas de lazer empregadas pelos jovens. Suas relações com o mundo estão cada vez mais interpeladas pela mídia e pelas novas tecnologias, usando e apropriando-se da mídia para diversos fins, inclusive para o lazer.

Se antes, no Brasil, a mídia e as novas tecnologias eram restritas às camadas altas e médias, o barateamento do custo e a expansão do consumo levaram à crescente utilização da mídia e de novas tecnologias pelas classes populares, sobretudo no segmento adolescente e jovem. 0 Instituto Brasileiro de Geografia e Estatística - IBGE (Brasil, 2009) destaca que o uso de internet cresceu, sobretudo, na população de estudante, passando de 35,7\% em 2005 para $60,7 \%$ em 2008. Entre os não estudantes também houve aumento, porém menor (de 15,9\% para 26,6\%). Com relação ao trabalho, a diferença de crescimento também é bem menor entre os ocupados (36\%) e os não ocupados (33,2\%). A pesquisa sugere que o acesso à internet está mais relacionado à condição de estudante do que com a situação da ocupação.

0 presente trabalho discute o lugar da mídia como forma de lazer para jovens de escolas públicas de Fortaleza. Por meio de uma pesquisa de base quantitativa, busca-se compreender as relações entre mídia e lazer na juventude da cidade de Fortaleza, sobretudo com relação à Internet, pois nos últimos anos tem crescido o número de usuários de computadores no Brasil, especialmente no segmento estudantil (Brasil, 2009).
O banco de dados quantitativos utilizado para a análise é proveniente da pesquisa Adolescência $e$ juventude: Estudo sobre Situações de Risco e Redes de Proteção em Fortaleza, realizada com 1140 adolescentes e jovens entre 14 e 24 anos de 43 escolas públicas de Fortaleza, por meio de um questionário autoaplicável e analisados através do software SPSS. 0 questionário possui 77 questões objetivas e duas subjetivas. 0 instrumento aborda temas tais como família, educação, trabalho, lazer, saúde e mídia. A aplicação ocorreu entre os anos de 2010 e 2011 (Colaço \& Cordeiro, 2013).

Os aspectos éticos que garantem a integridade dos participantes deste estudo foram assegurados por legislações brasileiras, tendo como base a Resolução no 196 do Conselho Nacional de Saúde, que consiste em diretrizes e normas que regulam as pesquisas com os seres humanos (BRASIL, 1996) e a Resolução no 016 do Conselho Federal de Psicologia (CFP, 2000). O Estatuto da Criança e do Adolescente também serviu de diretriz para a realização da pesquisa e para seus encaminhamentos, além do Termo de Consentimento Livre e Esclarecido, que foi assinado pelos pais ou responsáveis dos participantes menores de idade e pelos próprios jovens a partir de 18 anos. Todos os adolescentes e jovens das turmas escolhidas foram consultados acerca de seu interesse em participar do estudo, após serem devidamente esclarecidos sobre os objetivos da pesquisa e os procedimentos. É importante ressaltar que o projeto de pesquisa foi submetido à apreciação do Comitê de Ética na Pesquisa (CEP) da UFC, obtendo sua aprovação, no protocolo do COMEPE 265/09.

Assim, a presente pesquisa tem como objetivo discutir a relação lazer e mídia, com destaque para a internet, entre adolescentes e jovens de escolas públicas de Fortaleza. Além dos dados gerais, o trabalho correlaciona as formas de lazer com 
gênero (masculino e feminino) e idade (menoridade e maioridade).

\section{Considerações acerca da Adolescência, Juventude, Lazer e Mídia.}

As sociedades ocidentais a partir da segunda metade do século XX têm engendrado inúmeras mutações em termos culturais e subjetivos, com o advento das chamadas novas tecnologias, da virtualização do espaço, da comunicação planetária. Vivese a sociedade mediatizada (Moraes, 2006) articulada ao capitalismo pós-industrial (Jameson, 1993), que se ancora menos na produção de produtos do que no consumo de signos. Na relação entre a centralidade da mídia no cotidiano das populações de grandes centros urbanos, destaca-se o seu consumo pelo público mais novo, isto é, crianças e jovens. Eles parecem ter a relação com o mundo interpelada pela mídia e pelas novas tecnologias (Buchalla, 2009). No Brasil, a população jovem, entre 15 e 24 anos de idade, corresponde a $17,95 \%$ do total de habitantes (Brasil, 2010). Essa representatividade da população jovem também é significativa no Estado do Ceará, onde 19,75\% representa a parcela jovem da população.

As definições dos conceitos de Adolescência e Juventude são amplas e, muitas vezes, se sobrepõem. Ambos não são apenas conceitos historicamente construídos, mas que permanecem em constante transformação nos últimos cinco séculos. Segundo Ariès (1981), no medievo, a juventude significava a idade da força e do meio da vida, e era diferenciada da adolescência, até então confundida com a infância. Foi apenas no século XVII que se desenvolveu, no seio da família burguesa, a ideia de que a puberdade seria um marco para o início da adolescência, restringindo a infância ao seu sentido moderno. A juventude, por sua vez, foi se tornando uma preocupação de escritores, moralistas e políticos, que nela depositavam novos valores e esperanças. Neste contexto, a adolescência se tornou a idade preferida do século XX, se expandindo e empurrando a infância para trás e a maturidade para frente. (Fischer, 1996; Ariès, 1981). Normalmente o marco considerado para a consolidação da centralidade da juventude na cultura ocidental foi o período após a Segunda Guerra Mundial, onde ela passou a representar uma esperança em um futuro melhor e os movimentos políticos e, sobretudo, culturais, fundam uma "cultura juvenil" (Pais, 1990).
Há atualmente alguns critérios etários que diferenciam a infância, a adolescência e a juventude. 0 Estatuto da Criança e do Adolescente (BRASIL/ECA, 1990), por exemplo, demarca essa distinção no Art. $\mathrm{N}^{\circ} 2$, definindo criança como a pessoa de até 12 anos e adolescente aquele entre 12 e 18 anos. Através da constitucionalização dessa demarcação, torna-se mais fácil lidar com crianças e adolescentes do ponto de vista legal e de defesa de direito, sendo essa definição utilizada por muitas organizações. Entre a adolescência a e juventude há uma sobreposição de critérios de base etária. A Organização Mundial de Saúde (OMS) define a adolescência entre 10 e 19 anos enquanto a Organização das Nações Unidas (ONU) designa a juventude entre 15 e 24 anos. Segundo Eisenstein (2005), ainda é comum utilizar o termo jovens adultos "para englobar a faixa etária de 20 a 24 anos de idade (young adults)" (p. 6)

Mesmo considerando as limitações dos critérios etários, que circunscrevem a complexidade das vivências sociais, culturais e subjetivas de adolescentes e jovens a determinadas idades, a presente pesquisa adota o critério de classificar como adolescentes os sujeitos entre 14 e 17 anos, atravessados juridicamente por uma menoridade, e como jovens os sujeitos entre 18 e 24 anos. Desta forma, busca-se dialogar com classificações que vêm engendrando políticas públicas de assistência no Brasil, que se diferenciam no trato entre adolescência e juventude.

Em tempos hodiernos é perceptível a existência de uma centralidade no que concerne a assuntos vinculados à juventude, inclusive na participação nas economias de mercado através do poder de compra dos jovens, assim como dos produtos ofertados para este público. 0 jovem representa um padrão de beleza, um modo de vida, um modelo a ser seguido por todos que almejam sua prosperidade (Kehl, 2004). Ao se apropriar do discurso acerca da adolescência e juventude tornando-a uma fatia do mercado, a mídia ajudou a cunhar outros termos, como geração shopping center, teenagers e geração teen (Savage, 2009).

Entre a exaltação da "melhor fase da vida" e a tentativa de contenção das manifestações juvenis, o "mundo adulto" parece oscilar. Fraga (2000) afirma que "a juventude, destacada como símbolo de esperança no futuro, passa também a ser vista e tratada como uma ameaça pública a todas as gerações; principalmente como uma ameaça a si mesma" (p. 62). E é exatamente essa ameaça que tenta ser

Psicol. Argum. 2014, 32(79), Supl. 2, 29-43 
contida pelos governantes e suas políticas públicas, sobretudo quando o foco não é a juventude teen classe média presente na televisão, mas a juventude de classe popular. Sob-resquícios do Higienismo - movimento médico que provocou mudanças desde a organização familiar até as regras trabalhistas no Brasil no início do séc. XX - as concepções acerca da população de classe popular permanecem até os dias de hoje. A juventude de origem popular sofre uma constante contenção por parte da família, do Estado, da escola e de toda a sociedade para que não enverede por uma vida de atos infracionais. (Coimbra e Nascimento, 2003; Fraga, 2000). Muitas vezes o jovem pobre é visto como potencialmente criminoso.

A despeito das diversas formas de se viver a adolescência e a juventude, segundo Mazzarella (2009), a massificação da cultura a partir de diversas modalidades midiáticas tem gerado, nas últimas décadas, um pânico moral, levando à necessidade de se instrumentalizar a atividade de lazer do jovem, através da supervisão do adulto.

Acerca das definições sobre lazer, o Estatuto da Criança e do Adolescente (ECA) o discute como um direito a ser assegurado com absoluta prioridade, sendo dever da família, da comunidade, da sociedade e do poder público garantir acesso ao lazer para crianças e adolescentes. (Brasil/Eca, 1990).

Art. $4^{\circ}$ - É dever da família, da comunidade, da sociedade em geral e do poder público assegurar, com absoluta prioridade, a efetivação dos direitos referentes à vida, à saúde, à alimentação, à educação, ao esporte, ao lazer, à profissionalização, à cultura, à dignidade, ao respeito, à liberdade e à convivência familiar e comunitária.

O lazer está ligado ao tempo livre, "em oposição aos momentos de compromisso laboral ou de estudo, para crianças e adolescentes" (Marques, Dell'aglio \& Sarriera, 2009, p. 80), e elas podem se ocupar das mais diversas atividades, normalmente buscando liberdade, prazer e ócio.

Segundo Marques et al. (2009, p. 82), há na literatura tanto aqueles que atrelam tempo livre e juventude como fator de risco numa visão preconceituosa, sobretudo nas camadas populares, como pesquisas que analisam a importância do tempo livre como fator de proteção, por ajudar na promoção do desenvolvimento do indivíduo. Estes autores classificam o tempo livre da juventude em estruturado e não estruturado. $\mathrm{O}$ tempo livre estruturado é aquele "liderado por adultos, com encontros regulares, e com atividades que desenvolvem habilidades", enquanto que o não estruturado não é supervisionado, e sim coordenado por pares. Além de atuar como proteção no desenvolvimento, o lazer para os autores é um momento de descanso, de socialização e de desenvolvimento de habilidades e autonomia. Também é uma maneira de autorrealização e de compensação de necessidades. É neste domínio, o do lazer, que a juventude adquire maior visibilidade de expressão, produzindo diariamente suas próprias normas e expressões culturais. Portanto, para avaliar atividades de lazer é necessário sair da sala de aula e do contexto escolar.

Assim como foi dito sobre a diversidade acerca do conceito de juventude, existem também inúmeras formas de vivenciar e conceituar o lazer. Hack e Pires (2007) apresentam um estudo teórico sobre a relação existente sobre lazer, ora relacionado com juventude, ora relacionado com as mídias. Segundo as pesquisadoras, a ideia de lazer dentro das culturas juvenis "reflete os valores/funções de 'descanso', 'divertimento' e 'desenvolvimento pessoal', além de percepções que remetem ao caráter de cultura lúdica, num sentido que não privilegia a natureza daquilo que é feito, mas a maneira como é feito." (p. 6).

É possível estabelecer três categorias sobre lazer dentro das culturas juvenis. A primeira categoria aborda os "espaços de lazer" como locais típicos para as práticas culturais de lazer, agrupados em conjuntos naturais, comerciais, relacionais e públicos. Identificado na forma de espaços, o lazer expressa um amplo território marcado por relações socioeconômicas. A segunda categoria refere-se a "atitude" como uma variável "básica" para entendimento do lazer. Essa categoria descreve as dimensões das sensações, como relaxamento e distração. $\mathrm{O}$ lazer expresso como atitude retrata a experiência vivida de forma satisfatória. A terceira refere-se a "Lazer e tempos" nas culturas juvenis. Uma categoria constituída a partir do cotidiano em relação ao tempo para diferentes atividades, denominado como "tempos sociais". Portanto, para Hack e Pires (2007), o lazer é incorporado nesse tempo em contraste ao trabalho; assim, o lazer é exclusivo de momentos livres.

Bonato, Sarriera e Wagner (2012) relatam que o lazer gera preocupações, pois envolve aspectos relacionados com um desenvolvimento positivo do jovem e sua capacidade de enfrentamento das problemáticas 
pessoais e sociais. Resgatando a concepção de autores como Biss, Fagan, Franklin, Fuller e Simon ainda da primeira metade do século $\mathrm{XX}$, as preocupações giram em torno da maneira como o lazer é aproveitado, muitas vezes tutelado pelos pais ou responsáveis através de atividades salvaguardadas por eles. Essa tutela reflete que em vez de apoio social, esse tempo de dedicação para a diversão normalmente é visto como um problema para os tutores.

Como fenômeno social, as práticas de lazer ocorrem dentro de processos socializadores, ora dentro de instituições tradicionais, como família e escolas, ora em instituições alternativas, como ONGs (Formiga \& Souza, 2012). Dentro da dinâmica interpessoal dessas instituições, existe certo controle, especificamente da família, para com a promoção de comportamentos sociais que não sejam prejudiciais aos jovens e seus próximos. Para tanto, essas instituições, classificadas como socionormativas, agem promovendo responsabilidades e comportamentos, de maneira rígida ou negociada, nas relações sociais da juventude em direção à extinção de condutas consideradas desviantes.

Como citado inicialmente, a mídia tem ocupado cada vez mais espaço na sociedade e tem sido importante como a responsável pela constituição das identidades juvenis. Em recente estudo, baseado no mesmo banco de dados do presente trabalho, Miranda et al. (2013) discutiram a presença da mídia na sexualidade dos jovens. Televisão, mídia impressa e internet são constantes fontes de informação sobre sexo entre adolescentes e jovens.

O indivíduo da atualidade constrói sua subjetividade partindo de múltiplos e diferenciados fatores fragmentados entre si, dentre eles a mídia (Miranda, 2007; Miranda, Sampaio \& Lima, 2009). Na internet, por exemplo, os adolescentes têm mais autonomia para fazer e dizer o que pensam e desejam do que já tiveram historicamente (Stern \& Willis, 2009). A mídia situa e estimula formas de existências coletivas ou relações consigo mesmo e com o outro. 0 modo como as práticas juvenis são construídas e como a juventude constitui-se e está sendo constituída estabelece uma forte relação com a apropriação e identificação com aquilo que é veiculado pela mídia. Entretanto, este não é um processo passivo. A mídia é também fortemente influenciada e construída pela juventude, pois esta tem recorrido aos diversos instrumentos da mídia para o estabelecimento e fomento de comunicação para com seus pares, assim como a indústria da mídia reconhece a importância da juventude como consumidora e divulgadora da eficiência dos instrumentais midiáticos (Mazzarella 2009). Além disso, a mídia torna a juventude um produto a ser alcançado e apropriado pelas outras gerações etárias:

Na publicidade e nos produtos de todos os meios de comunicação, eles [adolescentes] adquirem centralidade, não só como modelo para outras gerações: mais do que nunca, o corpo jovem habita os sonhos e o ideal de beleza tanto das crianças como, principalmente, dos mais velhos (Fischer, 1996, p. 21).

A mídia também representa terrenos onde as gerações mais jovens, incluindo as crianças, fazem uma série de aprendizagens e adquirem competências, constroem imagens do mundo, comunicam e experimentam identidades. As mudanças tecnológicas, especialmente a expansão da internet, são também um fator significativo para a transformação das formas de engajamento político da juventude, criando formas de comunicação e participação social de grande originalidade (Boghossian e Minayo, 2009).

Baseado nas discussões acima, se percebe a existência de uma interligação entre a juventude, mídia e lazer. As formas de lazer desempenham um papel importante no estabelecimento das relações sociais da juventude e na criação de vínculos. Por estarmos vivendo em uma sociedade cada vez mais midiatizada (Moraes, 2006), os meios de comunicação, televisão, internet, celular, etc., também perpassam nos processos de subjetivação dos jovens, incluindo suas práticas de lazer. Reconhecendo a juventude como uma categoria sócio-histórica e, portanto, marcada por questões econômicas, culturais, sociais e subjetivas, a relação com a mídia encontra-se também presente inclusive nas classes populares. Os diferentes segmentos sociais da juventude, sejam advindos de classes altas e médias, sejam oriundos de classe popular, têm seu cotidiano interpelado pela mídia. Segundo Martin-Barbero (2008,), as pesquisas com jovens deveriam, então: "valorizar o lugar que ocupam as culturas audiovisuais e as tecnologias digitais, tanto na vida cotidiana de jovens quanto na configuração de imaginários de onde os jovens veem a si mesmos e na transformação de seus modos de estar juntos" (p. 13).

Considerando que os estudos sobre adolescência e juventude não podem excluir a mídia como tema

Psicol. Argum. 2014, 32(79), Supl. 2, 29-43 
relevante, a presente pesquisa analisa a relação lazer e mídia com estudantes de escolas públicas de Fortaleza.

\section{Método}

Material

Os dados quantitativos foram construídos com base na pesquisa Adolescência e juventude: Estudo sobre Situações de Risco e Redes de Proteção em Fortaleza, realizada com 1140 adolescentes e jovens entre 14 e 24 anos de 43 escolas públicas de Fortaleza, por meio de um questionário autoaplicável. O questionário possuía 77 questões objetivas e duas subjetivas. O instrumento aborda temas tais como família, educação, trabalho, lazer, saúde e mídia. A aplicação ocorreu entre os anos de 2010 e 2011. (Colaço e Cordeiro, 2013).

Foram considerados os limites de demarcadores etários, compreendendo, assim, como adolescentes os indivíduos entre 14 e 17 anos e como jovens os indivíduos entre 18 e 24 anos. No entanto, o demarcador socioeconômico encontra-se presente ao ter como sujeitos da pesquisa os estudantes da rede pública de ensino de Fortaleza, pois o ensino público neste município está relacionado às populações de classe popular que, segundo estudos de Sarreira, Tatin, Coelho e Bücker (2007), normalmente não desfrutam de variedade de opções de lazer. Um dos objetivos deste estudo, portanto, é verificar, além de sua relação com a mídia, o acesso que a juventude com menor poder aquisitivo tem ao lazer, evidenciado quais opções são as mais escolhidas, trazendo apontamentos e indagações a respeito dessas escolhas.

Para a realização da presente pesquisa, contou-se com estudantes matriculados no sétimo, oitavo e nono anos das escolas municipais e do sétimo ao terceiro ano das escolas estaduais e municipais da cidade de Fortaleza, incluindo os alunos da formação continuada em Educação de Jovens e Adultos (EJA). Como organização político-administrativa, Fortaleza é dividida em seis Secretarias Executivas Regionais (SER), cada uma composta por vários bairros. Considerando as seis regionais como unidades amostrais primárias, foram escolhidas aleatoriamente três escolas municipais e três estaduais em cada regional. Em seguida, partindo da população de alunos matriculados nas respectivas séries das redes municipais (32.237) e estaduais (142.696), selecionaram-se, aleatoriamente (intervalo de confiança $=95 \%$ e nível de significância $=0,04)$, os participantes do estudo em cada uma das redes de ensino. Eles foram distribuídos proporcionalmente em função do número total de matriculados em cada regional por série e tipo de escola (municipal e estadual). Ressalta-se que, a partir dos dados referentes à população dos sexos feminino e masculino da cidade de Fortaleza fornecidos pelo Instituto Brasileiro de Geografia e Estatísticas - IBGE (Brasil, 2000), dividiram-se os estudantes proporcionalmente em função do sexo (46,8\% do sexo masculino e 53,2\% do feminino).

Para tanto, o conhecimento dos aspectos demográficos, sociais, culturais, econômicos e de saúde desses segmentos constitui-se principal referência. No caso de adolescentes e jovens, torna-se ainda mais relevante, uma vez que representam uma parcela significativa da população brasileira; no censo de 2010 foram contabilizados 34.236 .060 jovens de 15 a 24 anos, isto é, 17,95\% (Brasil, 2010).

Para análise dos dados obtidos, utilizou-se o software SPSS, especializado em pesquisas estatísticas em Ciências Sociais, para facilitar as análises e correlações necessárias para embasar a pesquisa. Por meio de análises descritivas e análises bivariadas de significância com a ferramenta do Teste $t$ de amostras independentes, foram realizadas as seguintes correlações: lazer e gênero; e lazer e faixa etária.

\section{Resultados}

A maioria dos participantes da pesquisa $(57,9 \%)$ é do sexo feminino, próximo às porcentagens fornecidas pelo último censo do IBGE (Brasil, 2010), em que 51,04\% da população do Brasil, e do Ceará $51,25 \%$, é feminina. Quanto à idade, no intervalo de 14 a 24 anos, a maioria da amostra é composta por sujeitos de 14 a 17 anos (67,0\%). Uma parcela menor (32,9\%) é composta por jovens de 18 a 24 anos de idade. Em relação às identidades étnicas, a maior parte se identificou como pardo $(63,5 \%)$. De acordo com a Pesquisa Nacional por Amostra de Domicílios - PNAD (Brasil, 2010), as regiões Norte e Nordeste possuem a maioria de sua população (superior a $70 \%$ ) considerada parda. Verifica-se que o perfil da amostra, no que se refere à identificação étnica, se aproxima dos dados regionais observados na pesquisa nacional. 0 estado civil da maioria é solteiro (92,8\%), fato esperado, levando em conta a idade média da amostra (14 a 17 anos).

Em relação à renda, segundo a PNAD (Brasil, 2010), houve um aumento da renda familiar em 
relação a 2004 de cerca de 19\%, atingindo $\mathrm{R}$ \$ $2.085,00$, o que se aproxima dos dados constatados na pesquisa. É importante salientar que a maioria dos participantes $(65,5 \%)$ afirmou não saber esse dado, demonstrando o desconhecimento dos jovens da pesquisa quanto à renda de suas famílias, tornando, neste aspecto, difíceis as inferências mais precisas. Com relação ao sustento da casa, 90,7\% afirmou que outros membros da família, e não eles mesmos, contribuem. Isso pode estar relacionado ao fato de que a amostra da pesquisa é composta por estudantes, além de que estes, em sua maioria, são menores de idade. A amostra também indica que $55,8 \%$ dos estudantes asseguram receber algum tipo de bolsa, ou que sua família é beneficiada com algum auxílio referente a programas sociais de complementação de renda. Entre os que afirmaram receber auxílio, quase todos $(90,5 \%)$ são beneficiados com o Programa Bolsa Família.

De acordo com o Instituto Brasileiro de Geografia e Estatística - IBGE, através da Pesquisa Nacional por Amostras de Domicílios - PNAD de 2009 (Brasil, 2010), 32,8\% dos domicílios do país possuem quatro ou cinco moradores, enquanto que no nordeste o dado sobe para $34,9 \%$. No presente estudo, em relação ao número de pessoas que reside no domicílio, incluindo o respondente, metade da amostra $(50,8 \%)$ afirmou que cerca de quatro a cinco pessoas moram em suas residências. Tal dado pode ser relacionado à população da amostra desta pesquisa, composta pela população de baixa renda, fator que tem sido relacionado ao maior número de pessoas na família.

Para formular a avaliação do nível socioeconômicos dos participantes, o estudo considerou como modelo os itens utilizados no PNAD 2009 (Brasil, 2010). Nesse aspecto, ao responder o questionário, quase todos afirmaram que sua residência possui pelo menos um quarto $(99,04 \%)$ e um banheiro $(99,83 \%)$. Quanto aos aparelhos domésticos, a maioria afirma possuir pelo menos um aparelho de DVD (92,89\%), no mínimo uma TV em cores $(99,03 \%)$, pelo menos um aparelho de som ou rádio $(89,39 \%)$ e no mínimo uma geladeira $(96,23 \%)$. Por outro lado, a maior parte dos adolescentes e jovens diz não possuir máquina de lavar $(60,88 \%)$, computador $(63,07 \%)$ ou aspirador de pó $(81,84 \%)$ em casa ${ }^{1}$.

1 Os dados biossociodemográficos encontram-se publicados em Colaço \& Cordeiro, 2013.
Na realização do presente trabalho, foram escolhidos para análise os itens referentes ao lazer. Durante a análise das tabelas, cogitou-se a hipótese de que a forma como o lazer era vivenciado poderia apresentar diferenças de acordo com o gênero ou com a idade. Segundo o Projeto Pedagógico Integrado - PPI - do Pro Jovem Urbano (2008), a juventude que alcança a maioridade desenvolve preocupações quanto sua entrada no mercado de trabalho, portanto recorrendo a capacitações que os qualifiquem e os certifiquem, a fim de que alcancem a emancipação da família. Nas considerações sobre adolescência presentes no caderno socioeducativo do Pro Jovem Adolescente (2009), há uma reflexão interessante sobre os conflitos geracionais, em que adultos estranham a dita "rebeldia" dos adolescentes, que encontram-se inseridos num circuito complexo de informação, costumes e práticas. Dessa forma, verifica-se que a relação entre juventude e lazer é, ao longo do desenvolvimento etário, sobreposta pela preocupação dos jovens na entrada do mercado de trabelho, afim de que alcancem a emancipação da tutoria e controle dos familiares. Para investigar esta hipótese foi realizado um corte etário (dividido em dois grupos: de 14 a 17 anos e de 18 a 24 anos) e de gênero (masculino e feminino) nos itens analisados nesta pesquisa. Ao ser questionado sobre o que faz nos momentos em que não está trabalhando ou estudando (Tabela I), ou seja, em

Tabela 1 - Relação Adolescência/Juventude e Lazer (N = 1140).

\begin{tabular}{lcc}
\hline $\begin{array}{l}\text { O que você costuma fazer quando não } \\
\text { está estudando ou trabalhando? }\end{array}$ & f & \%* \\
\hline Assistir TV & 968 & 86,7 \\
\hline Ouvir ou tocar música & 849 & 76,1 \\
\hline Navegar na internet & 710 & 63,6 \\
\hline Descansar & 676 & 60,6 \\
\hline Namorar & 659 & 59,2 \\
\hline Passear & 639 & 57,3 \\
\hline Ler livros, revistas ou quadrinhos & 557 & 50,0 \\
\hline Praticar esportes & 467 & 41,8 \\
\hline Ir a festas & 445 & 39,9 \\
\hline Jogar/brincar & 406 & 36,4 \\
Cinema ou teatro & 390 & 35,0 \\
\hline Desenhar/pintar/artesanato & 193 & 17,3 \\
\hline Outros & 77 & 6,9 \\
\hline
\end{tabular}

*Porcentagem válida (desconsideram os alunos que não responderam)

Psicol. Argum. 2014, 32(79), Supl. 2, 29-43 
seu lazer, verifica-se que assistir TV é a atividade mais procurada, com $86,7 \%$ das pessoas que responderam ao item. Em seguida aparece "ouvir ou tocar música", com 76,1\%. "Navegar na Internet" ocupa a terceira posição na preferência dos jovens, com $63,6 \%$ dos que responderam. Inferindo que a relação com a música pode estar mediada por alguma mídia (rádio, celular, mp3 etc.), observa-se que as três principais atividades escolhidas pelos participantes da pesquisa envolvem produtos midiáticos. Descansar, namorar e passear também foram marcados pelos estudantes, ocupando, respectivamente, quarta, quinta e sexta posições. Observa-se também que ir ao cinema ou ao teatro não é uma opção muito frequente como atividade de lazer para o jovem. 0 subitem ficou a frente apenas de "desenhar/ pintar/ artesanato" e "outros".

Quanto ao gênero, a diferença entre homens e mulheres foi significativa do ponto de vista estatístico, em relação a alguns itens (Tabela II), com a prevalência da prática de esportes $(64,15 \%)$ e brincadeiras e jogos $(52,27 \%)$ entre os meninos. Entre as meninas, apenas $25,92 \%$ praticam esporte e $25,15 \%$ tem as brincadeiras e jogos como forma de lazer. Também há uma maior incidência de uso da internet entre os meninos $(67,17 \%)$ do que entre as meninas $(61,04 \%)$. No entanto, há entre as meninas uma incidência maior de ouvir ou tocar música $(78,37 \%)$ passeios $(60,58 \%)$ e ler livros, revistas ou quadrinhos $(55,21 \%)$. A incidência entre meninos é de $72,79 \%, 52,48 \%, 42,55 \%$, respectivamente. Em ambos, a televisão foi o item mais marcado, sem apresentar diferença significativa entre os gêneros.

Quanto ao corte etário, é interessante destacar que com o aumento da idade houve uma diminuição na resposta dos três itens em questão (Tabela III), baixando assistir TV (de 88,76\% para 82,51\%), ouvir música (de 78,98\% para 69,95\%) e navegar na internet $(66,40 \%$ para $57,65 \%)$. Tal informação pode indicar uma redução do lazer ou mesmo uma diminuição do interesse de acordo com a idade, assim como provavelmente ocorreu na redução do item jogar/brincar, que declinou de 40,03\% para 28,96\%. Embora com uma tendência a redução, nos demais itens não foram observadas diferenças significativas do ponto de vista estatístico.

Como foi dito anteriormente, a ascensão da internet enquanto mídia frequentemente utilizada pelo público jovem (Brasil, 2009) acarretou em um interesse por um detalhamento em seus dados, presentes nas tabelas apresentadas a seguir, que indagam o local de onde o acesso é realizado e a finalidade de seu uso. São questões importantes para a compreensão de como está ocorrendo a apropriação da internet.

Tabela 2 - Relação Lazer e Gênero (N = 1140).

\begin{tabular}{|c|c|c|c|c|c|c|}
\hline \multirow{3}{*}{$\begin{array}{l}\text { O que você costuma fazer quando } \\
\text { não está estudando ou trabalhando? }\end{array}$} & \multicolumn{4}{|c|}{ Sexo do respondente } & \multirow{2}{*}{\multicolumn{2}{|c|}{ Significância }} \\
\hline & \multicolumn{2}{|c|}{$\begin{array}{c}\text { Masculino } * \\
(n=463)\end{array}$} & \multicolumn{2}{|c|}{$\begin{array}{c}\text { Feminino * } \\
(n=652)\end{array}$} & & \\
\hline & Sim & $\%$ & Sim & $\%$ & $P \leq$ & V Cramer \\
\hline Assistir TV & 394 & 85,10 & 573 & 87,88 & - & - \\
\hline Ouvir ou tocar música & 337 & 72,79 & 511 & 78,37 & 0,05 & 0,066 \\
\hline Navegar na internet & 311 & 67,17 & 398 & 61,04 & 0,05 & 0,063 \\
\hline Descansar & 274 & 59,18 & 401 & 61,50 & - & - \\
\hline Namorar & 287 & 61,99 & 371 & 56,90 & - & - \\
\hline Passear & 243 & 52,48 & 395 & 60,58 & 0,01 & 0,082 \\
\hline Ler livros, revistas ou quadrinhos & 197 & 42,55 & 360 & 55,21 & 0,005 & 0,126 \\
\hline Praticar esportes & 297 & 64,15 & 169 & 25,92 & 0,005 & 0,385 \\
\hline Ir a festas & 199 & 42,98 & 245 & 37,58 & - & - \\
\hline Jogar/brincar & 242 & 52,27 & 164 & 25,15 & 0,005 & 0,278 \\
\hline Cinema ou teatro & 167 & 36,07 & 222 & 34,05 & - & - \\
\hline Desenhar/pintar/artesanato & 108 & 23,33 & 85 & 13,04 & 0,005 & 0,133 \\
\hline Outros & 32 & 6,91 & 44 & 6,75 & - & - \\
\hline
\end{tabular}

* Números válidos, desconsiderando os que não responderam. 
Tabela 3 - Relação Lazer e Idade (N = 1140).

\begin{tabular}{|c|c|c|c|c|c|c|}
\hline \multirow{3}{*}{$\begin{array}{l}\text { O que você costuma fazer quando não está } \\
\text { estudando ou trabalhando? }\end{array}$} & \multicolumn{4}{|c|}{ Idade do respondente } & \multirow{2}{*}{\multicolumn{2}{|c|}{ Significância }} \\
\hline & \multicolumn{2}{|c|}{$\begin{array}{c}14-17 * \\
(n=747)\end{array}$} & \multicolumn{2}{|c|}{$\begin{array}{c}18-24 * \\
(n=366)\end{array}$} & & \\
\hline & Sim & $\%$ & Sim & $\%$ & $P \leq$ & V Cramer \\
\hline Assistir TV & 663 & 88,76 & 302 & 82,51 & 0,005 & 0,086 \\
\hline Ouvir ou tocar música & 590 & 78,98 & 256 & 69,95 & 0,005 & 0,101 \\
\hline Navegar na internet & 496 & 66,40 & 211 & 57,65 & 0,005 & 0,085 \\
\hline Descansar & 456 & 61,04 & 217 & 59,29 & - & \\
\hline Namorar & 416 & 55,69 & 240 & 65,57 & 0,005 & 0,095 \\
\hline Passear & 433 & 57,97 & 204 & 55,74 & - & - \\
\hline Ler livros, revistas ou quadrinhos & 385 & 51,54 & 171 & 46,72 & - & - \\
\hline Praticar esportes & 317 & 42,44 & 148 & 40,44 & - & - \\
\hline Ir a festas & 281 & 37,62 & 162 & 44,26 & 0,05 & 0,063 \\
\hline Jogar/brincar & 299 & 40,03 & 106 & 28,96 & 0,005 & 0,108 \\
\hline Cinema ou teatro & 254 & 34,00 & 133 & 36,34 & - & - \\
\hline Desenhar/pintar/artesanato & 456 & 61,04 & 217 & 59,29 & - & - \\
\hline Outros & 57 & 7,63 & 20 & 5,46 & _- & - \\
\hline
\end{tabular}

* Números válidos, desconsiderando os que não responderam.

Com relação ao acesso, (Tabela 4) 60,4\% dos adolescentes e jovens responderam que se conectam à internet. Dentre estes, se verifica que grande parte dos adolescentes e jovens pesquisados utiliza lan house e cybercafé $(70,5 \%)$. Apenas 19,2\% acessam de casa. Esse dado se mostra coerente quando comparado ao perfil anteriormente apresentado, em que $72,7 \%$ das pessoas afirmam não ter computador em casa. $\mathrm{O}$ mesmo acontece em relação ao baixo acesso a partir do trabalho $(4,7 \%$ das pessoas que responderam ao subitem), em que se deve considerar que apenas $22,8 \%$ das pessoas que responderam afirmaram estar trabalhando, na ocasião da pesquisa.

Com relação ao gênero, considerando o $\mathrm{p}<0,001$ para que a análise seja significativa, não houve diferença significativa em nenhum local. Com relação ao corte etário, considerando o $\mathrm{p}<0,05$ para que a análise seja significativa, verificamos que, apesar de ainda ser o local mais procurado entre adolescentes e jovens, há uma diminuição do uso da lan house pelos mais velhos (73,93\% entre 14 e 17 anos e $62,89 \%$ para jovens de 18 a 24 anos) e um aumento no uso na escola e nos locais de trabalho. Tais dados encontram coerência com os outros da pesquisa, que constatou uma tendência a diminuição do lazer após a maioridade. (Tabela $\mathrm{V}$ )

Com relação às finalidades de utilização da internet, com possibilidade de múltiplas respostas, grande parte dos jovens afirmou acessar a internet para fazer trabalhos escolares $(83,5 \%)$, isto é, atividade não vinculada ao lazer. Outro principal motivo que faz com que o jovem se conecte à rede de computadores é a comunicação com pares $(81,5 \%)$. Baixar arquivos $(53,8 \%)$, buscar sites de interesse $(49,6 \%)$ e jogar $(38,7 \%)$ também fazem parte dos objetivos dos internautas participantes da pesquisa. Observa-se que as pessoas ainda acessam menos para criar blogs (9\%), comprar $(5,4 \%)$ e fazer outras atividades $(4,7 \%)$. (Tabela 6 )

Com relação à comparação entre gêneros, considerando o $\mathrm{p}<0,05$ para que seja significativa a análise, verificou-se que só não houve diferença significativa, do ponto de vista estatístico, para fazer/escrever blogs. Há, portanto, usos bem diferenciados entre meninos e meninas. Embora para ambos os gêneros predomine o uso para trabalhos escolares e comunicar-se com as pessoas, meninos fazem mais downloads de músicas,

Tabela 4 - Internet: local de acesso ( $\mathrm{N}=1.140)$.

\begin{tabular}{lccc}
\hline Itens & Níveis & F & \%* \\
\hline & $\begin{array}{c}\text { Lan house } \\
\text { cybercafé }\end{array}$ & 758 & 70,5 \\
Se você acessa a & Casa & 207 & 19,2 \\
internet, acessa de: & Escola & 163 & 15,2 \\
& Outro local & 58 & 5,4 \\
& Trabalho & 51 & 4,7 \\
\hline
\end{tabular}

*Porcentagem válida (desconsideram os alunos que não responderam)

Psicol. Argum. 2014, 32(79), Supl. 2, 29-43 
Tabela 5. - Relação entre local de acesso à Internet e critério etário ( $\mathrm{N}=1140)$.

\begin{tabular}{|c|c|c|c|c|c|c|}
\hline \multirow{3}{*}{ Se você acessa a internet, acessa de: } & \multicolumn{4}{|c|}{ Idade do respondente } & \multirow{2}{*}{\multicolumn{2}{|c|}{ Significância }} \\
\hline & \multicolumn{2}{|c|}{$\begin{array}{c}14-17 * \\
(n=721)\end{array}$} & \multicolumn{2}{|c|}{$\begin{array}{c}18-24 * \\
(n=353)\end{array}$} & & \\
\hline & Sim & $\%$ & Sim & $\%$ & $P \leq$ & V Cramer \\
\hline Casa & 136 & 18,86 & 70 & 19,83 & - & \\
\hline Escola & 96 & 13,31 & 66 & 18,70 & 0,05 & 0,071 \\
\hline Lan house, cybercafé & 533 & 73,93 & 222 & 62,89 & 0,005 & 0,113 \\
\hline Trabalho & 22 & 3,05 & 29 & 8,22 & 0,005 & 0,114 \\
\hline Outro local & 43 & 5,96 & 15 & 4,25 & - & \\
\hline
\end{tabular}

* Números válidos, desconsiderando os que não responderam.

jogos, filmes, jogam e navegam em sites de interesse e compram mais, se comparados ao gênero feminino. (Tabela 7)

Quanto ao critério etário, considerando o $p<0,005$ para que seja significativa a análise, verifica-se que houve diferença significativa apenas nos itens "fazer trabalhos da escola" e "jogar", indicando decréscimo de uso na medida em que aumentam a idade. Porém, tanto adolescentes entre 14 e 17, quanto jovens entre 18 e 24 tem os usos prioritários relacionados a comunicar-se com as pessoas e para trabalhos escolares. Para os menores de idade, o fazer trabalho escolares permanece em primeiro lugar e a comunicação em segundo. Situação inversa no uso dos maiores de 18 anos. O declínio do uso dos jogos on-line também corrobora com a discussão da diminuição do lazer para os jovens após 18 anos. Infere-se que, com o aumento da idade, o jovem de escola pública tem menos tempo para se dedicar à internet como fonte de lazer justificado pelas

Tabela 6 - Finalidades de uso da internet $(n=1.140)$.

\begin{tabular}{|c|c|c|c|}
\hline Item & Níveis & f & $\% *$ \\
\hline \multirow{8}{*}{$\begin{array}{l}\text { Se você usa a } \\
\text { Internet, você a } \\
\text { utiliza para: }\end{array}$} & $\begin{array}{c}\text { Me comunicar com as } \\
\text { pessoas }\end{array}$ & 883 & 81,5 \\
\hline & Baixar músicas, jogos, filmes & 583 & 53,8 \\
\hline & Fazer trabalhos da escola & 905 & 83,5 \\
\hline & $\begin{array}{l}\text { Navegar em sites de meu } \\
\text { interesse }\end{array}$ & 537 & 49,6 \\
\hline & Fazer/escrever blogs & 98 & 9,0 \\
\hline & Jogar & 419 & 38,7 \\
\hline & Comprar coisas & 59 & 5,4 \\
\hline & Outra atividade & 51 & 4,7 \\
\hline
\end{tabular}

Nota: *Porcentagem válida (desconsideram-se os alunos que não responderam). Os participantes podem responder mais de uma opção, o que explica o fato de a frequência e a porcentagem serem superiores a 1.140 e a $100 \%$, respectivamente. exigências sociais e culturais de outras formas de ocupação que visem outros benefícios para o indivíduo, tendo como exemplo o trabalho; entretanto, esta hipótese necessita ser mais bem estudada em pesquisas futuras.

\section{Discussão}

Os dados encontrados apresentam uma alteração com relação à primeira fase da pesquisa nacional (Marques et al., 2009), pois nesta, em primeiro lugar, ficou ouvir ou tocar música (76,5\%); em segundo, assistir TV (71,8\%); em terceiro, namorar (61,1\%). Navegar na internet ficou em nono lugar, com $27,8 \%$. Nota-se aí um aumento significativo do uso do computador no lazer do jovem estudante de escola pública.

Entretanto, algumas informações corroboram com outras pesquisas (UNICEF, 2007; Abramo \& Branco, 2008). Na pesquisa realizada pelo UNICEF, o lazer do jovem dividiu-se em assistir televisão (35\%), praticar esportes (33\%) e ouvir música (24\%) (UNICEF, 2007) e quanto menor a escolaridade, maior o tempo gasto na televisão. A pesquisa "Perfil da juventude brasileira" realizada em 2003 (Abramo \& Branco, 2008), dentre outros fatores, avaliou a fruição cultural e lazer e as preferências de mídia. Também com possibilidade de resposta múltipla, a televisão apareceu como lazer principal durante a semana (91\%), seguida de ouvir rádio $(89 \%)$ e encontrar amigos $(82 \%)$. Nos finais de semana, há apenas uma inversão dos três primeiros lugares, em que encontrar amigos assume o primeiro lugar $(90 \%)$, seguida de ouvir rádio $(89 \%)$ e assistir TV $(87 \%)$. No entanto, o item navegar na Internet, que na presente pesquisa assumiu um lugar de destaque $(63,6 \%)$, na pesquisa de Abramo e Branco (2008) 
Tabela 7 - Finalidade do uso da Internet / gênero ( $N=1140)$.

\begin{tabular}{|c|c|c|c|c|c|c|}
\hline \multirow{3}{*}{ Se você usa a Internet, você utiliza para: } & \multicolumn{4}{|c|}{ Sexo do respondente } & \multirow{2}{*}{\multicolumn{2}{|c|}{ Significância }} \\
\hline & \multicolumn{2}{|c|}{$\begin{array}{c}\text { Masculino * } \\
(n=451)\end{array}$} & \multicolumn{2}{|c|}{$\begin{array}{c}\text { Feminino * } \\
(\mathrm{n}=632)\end{array}$} & & \\
\hline & Sim & $\%$ & Sim & $\%$ & $P \leq$ & V Cramer \\
\hline Comunicar-me com as pessoas & 353 & 78,27 & 529 & 83,70 & 0,05 & 0,075 \\
\hline Baixar músicas, jogos, filmes & 312 & 69,18 & 270 & 42,72 & 0,005 & 0,262 \\
\hline Fazer trabalhos da escola & 357 & 79,16 & 547 & 86,55 & 0,005 & 0,098 \\
\hline Navegar em sites de interesse & 247 & 54,77 & 289 & 45,73 & 0,005 & 0,090 \\
\hline Fazer/ escrever blogs & 38 & 8,43 & 59 & 9,34 & - & \\
\hline Jogar & 248 & 54,99 & 170 & 26,90 & 0,005 & 0,287 \\
\hline Comprar coisas & 36 & 7,98 & 23 & 3,64 & 0,005 & 0,095 \\
\hline Outra atividade & 28 & 6,21 & 23 & 3,64 & 0,05 & 0,06 \\
\hline
\end{tabular}

* Números válidos, desconsiderando os que não responderam.

permaneceu em penúltimo lugar $(17 \%)$, e nos finais de semana em último, com o mesmo percentual, ficando mais próxima do índice encontrado na primeira fase da pesquisa. Supõe-se que essa diferença tenha se dado por conta do intervalo temporal de ambas com a presente pesquisa, pois nos últimos anos, segundo a Pesquisa Nacional por Amostra de Domicílios, PNAD (Brasil, 2009), aumentou em 77,3 o percentual de brasileiros de dez anos ou mais de idade que acessaram ao menos uma vez a Internet pelo computador. Este aumento foi maior no público jovem, entre 15 e 17 anos $(62,9 \%)$, e mesmo ainda havendo muita diferença de acesso entre as camadas sociais, cresceu o acesso das classes populares.

Segundo Fischer (2005), a TV aberta continua sendo a grande fonte de lazer e informação para a maioria da população, tanto do gênero feminino, como do masculino. A televisão oferece uma abertura para o mundo, uma possibilidade de acesso a informações imediatas sobre acontecimentos de diferentes pontos do planeta. Ouvir música é um caso especial, pois é uma mídia de fácil acesso e que perpassa os diversos meios de comunicação, estando essa prática historicamente presente no cotidiano da população desde a época em que não existiam tecnologias que facilitavam sua reprodução, como as apresentações ao vivo, até a invenção do rádio, da televisão e da internet, que facilitaram a difusão desse conteúdo. Atualmente, tecnologias como o MP3, o celular e Ipod, além das já citadas, permitem a inserção simultânea da música com outras atividades, tornando-a potencialmente presente a qualquer

Tabela 8 - Finalidade de uso da Internet e critério etário ( $\mathrm{N}=1140$ ).

\begin{tabular}{|c|c|c|c|c|c|c|}
\hline \multirow{3}{*}{ Se você usa a Internet, você utiliza para: } & \multicolumn{4}{|c|}{ Idade do respondente } & \multirow{2}{*}{\multicolumn{2}{|c|}{ Significância }} \\
\hline & \multicolumn{2}{|c|}{$\begin{array}{c}14-17 * \\
(n=735)\end{array}$} & \multicolumn{2}{|c|}{$\begin{array}{c}18-24 * \\
(n=347)\end{array}$} & & \\
\hline & Sim & $\%$ & Sim & $\%$ & $P \leq$ & V Cramer \\
\hline Comunicar-me com as pessoas & 608 & 82,72 & 273 & 78,67 & - & \\
\hline Baixar músicas, jogos, filmes & 400 & 54,42 & 182 & 52,45 & - & \\
\hline Fazer trabalhos da escola & 631 & 85,85 & 272 & 78,39 & 0,005 & 0,094 \\
\hline Navegar em sites de interesse & 371 & 50,48 & 165 & 47,55 & - & \\
\hline Fazer/ escrever blogs & 74 & 10,07 & 24 & 6,92 & - & \\
\hline Jogar & 319 & 43,40 & 99 & 28,53 & 0,005 & 0,144 \\
\hline Comprar coisas & 38 & 5,17 & 21 & 6,05 & - & \\
\hline Outra atividade & 38 & 5,17 & 13 & 3,75 & - & \\
\hline
\end{tabular}

* Números válidos, desconsiderando os que não responderam.

Psicol. Argum. 2014, 32(79), Supl. 2, 29-43 
momento, de acordo com a disponibilidade de tempo do indivíduo.

Embora as duas primeiras posições mais votadas sejam ocupadas pelas mídias televisão e música, a internet já assume uma posição de destaque com $63,6 \%$. A internet não substitui o uso de nenhuma outra mídia, mas em vez disso complementa muitas outras atividades dos adolescentes, incluindo assistir televisão, fazer a lição de casa, ouvir música (como foi falado acima) e falar ao telefone. Além de facilitar o acesso a diversos tipos de mídia, a internet também tem uma importante função social. De acordo com Stern e Willis (2009), a internet propicia um espaço para que os jovens lidem com suas relações sociais e com estilos de autoexpressão, assim como facilita a sensação de controle sobre suas interações sociais, na medida em que, no contato online, a qualquer momento é possível abandonar o diálogo. A lan house surge então como um espaço privilegiado, não apenas por garantir um fácil acesso devido ao baixo preço, mas também por ser um lócus de notável estabelecimento de relações sociais. Para Barros (2011), entra-se na lan house para acessar a internet, mas também para encontrar os amigos em um ritual de sociabilidade. Entre os jovens, é comum dar uma passada por lá. Vários frequentadores têm computador em casa, mas preferem ir à lan house para fazer um programa em grupo.

O ambiente nas lan houses é de muita conversa e brincadeiras, devido à importância das atividades lúdicas nesses espaços, como jogos e músicas. .... Os frequentadores vivenciam o espaço da Lan com um clube local (Barros, 2009) onde se exercita a sociabilidade em atividades lúdicas compartilhadas. (p.3)

Segundo Barros (2011), devido ao desinteresse das meninas em jogos e games, há uma diferença bastante significativa desse tipo de atividade de acordo com o gênero, e nesta pesquisa isto é evidenciado através da informação de que apenas 26,90 \% das meninas utilizam a internet para jogar; em contrapartida, 54,99\% dos meninos responderam afirmativamente a este item. A autora conclui que ao adentrar no espaço da lan house, é a sociabilidade juvenil masculina que é marcante; isso não quer dizer que as meninas não utilizem este espaço. Ao contrário, a lan house foi votada como o espaço mais utilizado para acessar a internet, assim como para os meninos. $\mathrm{O}$ que se pode inferir é que o uso feminino da internet é mais limitado e é menos focado em atividades de lazer, tornando o uso e a apropriação do espaço da lan house diversificado de acordo com o gênero, pois os objetivos desse uso são distintos. Os dados mostram que as meninas superam os meninos no uso da internet apenas nas práticas de fazer trabalhos da escola, comunicar-se com outras pessoas e em fazer/escrever blog, entretanto nesta última a diferença não é significativa e a primeira não constitui uma atividade de lazer.

Outro fator que chama a atenção na presente pesquisa é a baixa incidência de acesso a outros bens culturais, como por exemplo ir ao cinema ou teatro (35\% no total). Na pesquisa "Perfil da juventude brasileira” (Abramo \& Branco, 2008), 39\% dos jovens disseram jamais ter ido ao cinema. 0 percentual é ainda maior, por exemplo, com relação à ida a biblioteca (52\%), show (59\%), teatro (62\%) e museu (69\%). Na pesquisa Jovem Brasil, encomendada pelo UNICEF (Vivarta, 2004), adolescentes e jovens disseram preferir a televisão no lazer devido tanto "a falta do que fazer", "para ter informação", "para me divertir", "para relaxar ou para não pensar em problemas":

Não se pode esquecer que "falta do que fazer" significa, para jovens das classes menos favorecidas na escala social, literalmente a ausência de alternativas de lazer. A isto se soma ainda o fato de que muitos desses jovens, nos grandes centros urbanos, vivem acuados pela ameaça de violência. (p. 13)

Assim como as demais pesquisas, chama a atenção a falta de acesso dos jovens de classe popular a atividades culturais ligadas ao lazer, como cinema e teatro, que são de custo elevado. Pode-se inferir que eles acabam por ter acesso aos lançamentos de cinema através de cópias em DVD (piratas ou não) que são vendidas com facilidade nas ruas e lojas da cidade.

\section{Consideracões finais}

A análise dos dados indica que o uso da mídia como forma de lazer é corrente na vida dos jovens desta pesquisa. Apesar de estarmos vivendo em uma sociedade cada vez mais midiatizada, a escolha da mídia como forma de entretenimento muitas vezes pode sugerir a falta de outras opções e ofertas culturais, como ir ao teatro ou a shows. Assim como 
pesquisas anteriores indicam (Abramo \& Branco, 2008; Marques et al., 2009), a presente pesquisa corrobora com a necessidade de ampliação de acesso a bens culturais para os jovens em Fortaleza e no Brasil como um todo. O uso da internet em Lan house como local de sociabilidade e para a comunicação também pode sugerir a falta de outros lugares onde estes jovens possam se encontrar. Alem disso, verifica-se uma situação contrastante. Em meio à divulgação e propagação cultural da relevância da chamada "inclusão digital" atrelando-a com a capacitação profissional da juventude, formação cultural e intelectual e acesso livre a meios de comunicação e informação, verifica-se que essa mesma juventude ainda necessita recorrer aos espaços comerciais para acessar a internet, mesmo dispondo, em suas escolas, de laboratórios de informática ou de redes de compartilhamento coletivo de internet, como Wireless. A pesquisa, em comparação com outras similares anteriores, indica um uso crescente do computador como fonte de lazer para adolescentes e jovens.

Atentando-se para os recortes estabelecidos de gênero e idade, verifica-se que as questões analisadas sugerem que apesar do aumento de igualdades entre gêneros, homens e mulheres ainda tem formas de entretenimento variadas, com destaque para a prática de esporte e jogos entre o gênero masculino. No lazer mediado pela mídia, em ambos, destaca-se a televisão. No entanto, ainda há diferença na utilização da internet, tanto como destaque na hora do lazer, quanto como consumo de jogos online entre o gênero masculino. Ao analisar o recorte etário, verifica-se uma diminuição do lazer entre os jovens mais velhos, que se supõe que esteja relacionada com a entrada no mercado de trabalho.

Por fim, após um levantamento de informações teóricas e quantitativas, sendo subtemida uma análise convergente de ambos, verifica-se uma relação complexa entre a juventude de classe popular, suas práticas de lazer e a mídia. Os resultados da pesquisa fornecem, então, um perfil da juventude abordada analisando características e relações que envolvem as práticas de lazer e o uso de mídias, bem como seu acesso, consumo e espaços de apropriação, levando em consideração os fatores gênero e idade. Constata-se que a juventude depõe de poucos espaços livres de acesso ao lazer, sendo a mídia, mesmo com suas restrições, o espaço significativo para esse segmento.

\section{Agradecimento}

Ao Conselho Nacional de Pesquisa (CNPq), pelo financiamento da pesquisa.

\section{Referências}

Abramo, H. W., \& Branco, P. P. M. (Orgs.). (2008). Retratos da juventude brasileira: análises de uma pesquisa nacional. São Paulo: Perseu Abramo.

Ariès, P. (1981). História social da criança e da família (2a ed.). Rio de Janeiro: LTC.

Barbero, J. M. (2008). A mudança na percepção da juventude: sociabilidades, tecnicidades e subjetividades entre os jovens. In S. H. S. Borelli \& J. F. Filho. (Orgs.). Culturas juvenis no século XXI (pp. 9-32). São Paulo: Educ.

Barros, C. (2011). Interações e alteridade nas apropriações de redes sociais e games: um estudo em lan house popular. Revista Iluminuras, 12(27), 1-14.

Boghossian, C. O., \& Minayo, M. C. S. (Eds.). (2009). Revisão sistemática sobre juventude e participação nos últimos 10 anos. Saúde Sociedade, 18(3), 411-423.

Bonato, T. N., Sariera, J. C., \& Wagner, A. (2012). O lazer na adolescência. In J. C. Sarriera \& Â. C. Paradiso (Org.). Tempo livre e lazer na adolescência: promoção da saúde, intervenção e pesquisa (pp. 97-124). Porto Alegre: Sulina.

Brasil. (1990). Lei Federal n. 8.069/1990 - Estatuto da criança e do adolescente. Brasília: Conanda. Recuperado em 16 de Janeiro de 2013, de http:// www.planalto.gov.br/ccivil_03/leis/L8069.htm

Brasil. (1996). Resolução no 196/1996 do Conselho Nacional de Saúde. Brasília: Ministério da Saúde, 1996. Recuperado em 20 feveiro de 2010, de http:// conselho.saude.gov.br/

Brasil. (2000). Censo 2000. Recuperado em 8 de julho de 2011, de http://www.ibge.gov.br/home/estatistica/ populacao/censo2000/tendencias_demograficas/ tendencias.pdf

Brasil. (2009). Instituto Brasileiro de Geografia e Estatística - IBGE. De 2005 para 2008, acesso à internet aumenta 75,3\%. [Notícia eletrônica]. Recuperado em 17 de Abril de 2012, de http://www.ibge.gov. br/home/presidencia/noticias/noticia_visualiza. php?id_noticia=1517.

Psicol. Argum. 2014, 32(79), Supl. 2, 29-43 
Brasil. (2010) Censo 2010. Recuperado em 20 de julho de 2013, de http://www.censo2010.ibge.gov.br/ sinopse.

Buchalla, A. P. (2009). A juventude em rede. Revista Veja, 42(7), 84-93.

Conselho Federal de Psicologia. (2000). Resolução noㅜ 016. Recuperado em 01 de dezembro de 2014, de http://www.crpsp.org.br/portal/orientacao/resolucoes_cfp/fr_cfp_016-00.aspx

Coimbra, C., \& Nascimento, M. L. (2003). Jovens pobres: o mito da periculosidade. In P. Fraga, \& J. A. Iulianelli (Orgs.). Jovens em Tempo Real (pp.19-37). Rio de Janeiro: DP\&A.

Colaço, V. F. R., Cordeiro, A. C. F., Germano, I. M. P., Miranda, L. L., \& Bonfim, Z. A. C. (2011). Adolescência e juventude: estudo sobre situações de risco e redes de proteção em Fortaleza (Relatório de Pesquisa CNPq). Fortaleza: Departamento de Psicologia, Universidade Federal do Ceará. Recuperado em 01 de agosto de 2013, de http://www.dvprppg.ufc.br/pospsi.ufc.br/ images/Documentos/casadinho.pdf.

Colaço, V. F. R., \& Cordeiro, A. C. F. (Orgs.). (2013). Adolescência e juventude: conhecer para proteger. São Paulo: Casa do psicólogo.

Eisenstein, E. (2005). Adolescência: definições, conceitos e critérios. Adolescência \& Saúde, 2(2), 6-7.

Fischer, R. M. B. (1996). Mídia e produção de subjetividade. Tese de Doutorado, Universidade Federal do Rio Grande do Sul, Porto Alegre.

Fischer, R. M. B. (2005) Mídia e juventude: experiências do público e do privado na cultura. Cadernos CEDES, 25(65), 43-58.

Formiga, N. S., \& Souza, M. A. (2012). Grupos socionormativos, hábitos de lazer e condutas desviantes: uma perspectiva psicossocial a partir de modelos causais. In J. C. Sarriera e Â. C. Paradiso (Orgs.). Tempo livre e lazer na adolescência: promoção da saúde, intervenção e pesquisa (pp. 155-188). Porto Alegre: Sulina.

Fraga, A. B. (2000). Corpo, Identidade e Bom-Mocismo: cotidiano de uma adolescência bem-comportada. Belo Horizonte: Autêntica.

Hack, C. \& Pires, G. L. (2007). Lazer e mídia no cotidiano de culturas juvenis. Licere, 10(1), 1-11.
Jameson, F. (1993). O pós-modernismo e a sociedade de consumo. In A. Kaplan (Org.). O mal estar no pós-modernismo (pp. 25-44). Rio de Janeiro: Jorge Zahar.

Kehl, M. R. (2004). A juventude como sintoma da cultura. In R. J. Ribeiro, R. Novaes, P. Vannuchi. (Orgs.). Juventude e sociedade: trabalho, educação, cultura e participação (pp.89-114). São Paulo: Perseu Abramo.

Marques, L. F., Dell'aglio, D. D., \& Sarriera, J. S. (2009). 0 tempo livre na juventude brasileira. In R. M. Libório \& S. H. Koller (Orgs.). Adolescência e juventude: risco e proteção na realidade brasileira (pp.79-106). São Paulo: Casa do psicólogo.

Martín-Barbero, J. (2008). A mudança na percepção da juventude: sociabilidades, tecnicidades e subjetividades entre os jovens. In S. H. S. Borelli \& J. F. Filho. (Org.). Culturas juvenis no século XXI (pp. 9-32). São Paulo: EDUC.

Mazzarella, S. R. (2009) . Porque todos estão sempre perseguindo os jovens? In Os jovens e a mídia: 20 questões (S. M. M. da Rosa, trad.). Porto Alegre: Artmed.

Ministério do Desenvolvimento Social e Combate à Fome. (2009). Adolescências, juventudes e socioeducativo: concepções e fundamentos. Brasília, DF: Autor.

Miranda, L. L. (2007). Reflexões sobre educação, pós-mídia e produção de subjetividade no contexto escolar. In: A. Marcondes, A. Fernandes, \& M. Rocha. (Orgs.). Novos possíveis no encontro da psicologia com a educação (pp. 1-226). São Paulo: Casa do Psicólogo.

Miranda, L. L., Sampaio I. V., \& Lima, T. R. (2009). Fazendo mídia, pensando educação: reverberações no mesmo canal. Comunicação \& Sociedade, 30(51), 89-112.

Miranda, L. L., Khouri, M., Rodrigues, P., Araujo, I., Viana, D., Pinheiro, N., Gonçalves, S., Barros, J. P. (2013) Juventude, sexualidade e mídia: aspectos analisados no município de Fortaleza. In V. Colaço, \& A. Cordeiro (Orgs.). Adolescência e juventude: conhecer para proteger (pp.199-236). São Paulo: Casa do psicólogo.

Moraes, D. (2006). (Org.). Sociedade midiatizada. Rio de Janeiro: Maud.

Pais, J. M. (1990). A construção sociológica da juventude - alguns contributos. Análise Social, Instituto de Ciências Sociais da Universidade de Lisboa, 25, (105-106). 
Projeto Pedagógico Integrado do ProJovem Urbano (2008). Brasília: Programa Nacional de Inclusão de Jovens. ProJovem Urbano.

Sarreira, J. C., Tatin, D. C., Coelho, R. S., \& Bücker, J. (2007) Uso do tempo livre por adolescentes de classe popular. Psicologia: Reflexão e Crítica, 20(3), p. 361-367. Recuperado em 01 de dezembro de 2014, de http:// www.scielo.br/scielo.php?script=sci_arttext\&pid=S $010279722007000300003 \& \operatorname{lng}=$ pt\&nrm=iso\&tlng $=\mathrm{pt}$

Savage, J. (2009). A criação da juventude: como o conceito de teenager revolucionou o século XX. Rio de Janeiro: Rocco.
Stern, S. R., Willis, T. J. (2009). 0 que os adolescentes estão querendo on-line? In S. R. Mazarella. (Org.). Os jovens e a mídia 20 questões (S. M. M. da Rosa, trad.). Porto Alegre: Artmed.

Unicef. (2007). Adolescentes e jovens do Brasil: participação social e política. Recuperado em 11 de julho de 2011, de: http://www.unicef.org/brazil/pt/ voz2007.pdf.

Vivarta, V. (2004). Remoto controle: linguagem, conteúdo e participação nos programas de televisão para adolescentes. São Paulo: Cortez.

Psicol. Argum. 2014, 32(79), Supl. 2, 29-43 